\title{
Opinion paper: livestock agroecosystems provide ecosystem services but not their components - the case of species and breeds
}

\author{
D. Martin-Collado ${ }^{1,2} \odot$, P. Boettcher ${ }^{3}$ and A. Bernués ${ }^{1,2 \dagger}$ ๑
}

${ }^{1}$ Departamento de Producción y Sanidad Animal, Centro de Investigación y Tecnología Agroalimentaria de Aragón, Zaragoza, Spain; ${ }^{2}$ Instituto Agroalimentario de Aragón -IA2- (CITA-Universidad de Zaragoza), Zaragoza, Spain; ${ }^{3}$ Animal Production and Genetic Unit, Animal Production and Health Division, Food and Agriculture Organization of the United Nations (FAO), 00153 Rome, Italy

From an agroecological perspective, all livestock farming systems constitute agroecosystems. Depending on the type and intensity of human intervention (e.g. land use and farming practices), agroecosystems provide different combinations of ecosystem services (ES - tangible and intangible benefits) and disservices (negative externalities) to society. Livestock species and breeds constitute key components of agroecosystems but, as such, do not deliver ES. Rather, it is the specific way in which species and breeds are integrated in agroecosystems, that is, the interaction between animals and ecological processes, which delimits their contribution to the flow of ES from agroecosystems to society.

The ES framework is increasingly used to boost social and political support for less intensive production systems (e.g. pastoral, mountain, transhumant, low input-low output systems; collectively referred to as 'pastoral' in this document), by highlighting the whole range of functions they provide, with a special focus on public goods. Recently, the ES framework has also been used to highlight the role that local breeds play in delivering ES (e.g. Ovaska and Soini, 2016; Leroy et al., 2018; Marsoner et al., 2018). However, the theoretical foundations of the ES framework can be easily misinterpreted. In the domain of animal sciences, it is critical to distinguish the exact role that the breed, the species and the farming practices play in delivering ES. In this paper, we try to delimit these roles. To this end, we first discuss the ES concept and its integration in the wider framework of complex socio-ecological systems, which specially considers human-nature interactions. Second, we analyse the contributions of breeds and species to ES delivery. Finally, we caution that these contributions should not be overemphasized.

\section{Pastoral livestock farming as a complex social-ecological system}

The ES concept allows connecting livestock agroecosystems with human well-being. The 'cascade' model (Haines-Young

\footnotetext{
${ }^{\dagger}$ E-mail: abernues@aragon.es
}

and Potschin, 2010) is particularly useful for structuring this connection. This model spans the transition in sequential steps from ecosystem structures and processes to ecosystem functions, ES, human benefits and finally to human values. The distinction between benefits (e.g. provision of food products) and values (e.g. the social perception about the way food is produced) is key, since most market strategies to support pastoral systems and local breeds try to add value to food products by including their extrinsic quality attributes (those that do not depend on the product itself, but on the production system).

The role that pastoral livestock production plays in rearranging the ES delivered from agroecosystems to society, and the role of specific farming practices, species and breeds in this delivery, needs clarification. For this, we propose to embed the ES concept within the theory of complex social-ecological systems, which helps elucidate how human and natural systems relate to each other (Liu et al., 2007). The framework depicted in Figure 1 integrates the social and ecological systems placing the farms, species and breeds in their intersection. They function as filters or modulators of many agroecosystem processes and functions, modifying the natural flow of ES from the agroecosystem to society. On the one hand, farms benefit from provisioning ES (e.g. forage) and regulating ES (e.g. soil fertility or water availability) and allow for the delivery of new provisioning (e.g. meat or milk) and culturalES (e.g. related to breeds) to society, while modifying the flow of other ES (e.g. carbon sequestration by pastures) and biodiversity. On the other hand, farming practices (including the choice of species and breeds) modify the ecosystem structure and functioning, which can also cause ecosystem disservices (e.g. reduction of water availability). The particularities of the farming practices (e.g. grazing management), species (e.g. type of food products) and breeds (e.g. adaptation to specific environmental conditions) modify in different ways the ES flow. Of particular relevance are the demands of society at large (e.g. how the agrifood system operates) and consumers (e.g. how animal food is produced), which should shape the farming practices (and policies) that affect agroecosystem structure and processes. 


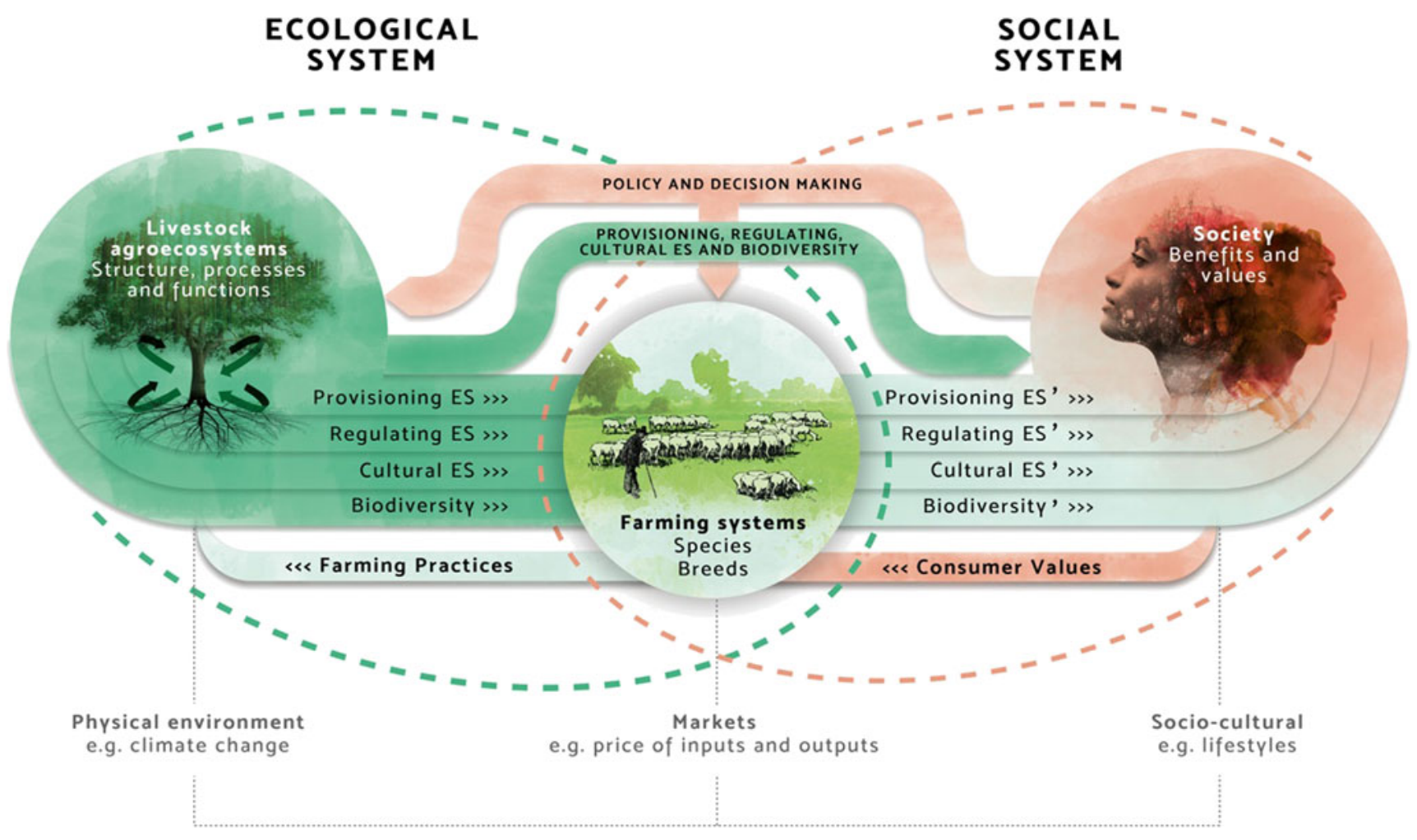

EXTERNAL DRIVERS

Figure 1 (colour online) Adaptation of the complex social-ecological systems framework to livestock agroecosystems. ES=ecosystem services.

\section{Breeds and ecosystem services}

The main challenge in identifying the links between ES and breeds (and species) is to correctly identify the role they have in the ES delivery, since the 'delivery unit' is the agroecosystem in which they embedded, not the breed itself. Marsoner et al. (2018) establish a direct relationship between the number of local breeds in a territory and the cultural heritage, equating the cultural value of each breed independently of the species, the specific cultural manifestation, the society perceptions of those cultural elements or, more importantly, the characteristics of the agroecosystem in which the breed is embedded. Similarly, Ovaska and Soini (2016) describe ES that are 'provided' by native breeds, referring to ES that are actually linked to farming systems and practices or to livestock in general. Leroy et al. (2018) acknowledge that ES are provided by agroecosystems, which are impacted by the breeds they contain. However, they conclude that a majority of provisioning, regulating and cultural ES are provided by locally adapted breeds without clearly clarifying their exact role, referring sometimes to farming systems, animal genetic resources or traits as providers of ES. In our view, a breed (or a group of breeds with similar characteristics) should only be considered linked to a specific ES when the delivery of this ES is substantially modified if the breed is substituted in the agroecosystem. Particular breeds are sometimes closely associated with specific farming systems, which would change if the breed was substituted (e.g. North Ronaldsay sheep in seaweed feed-based farming systems in Scotland). Only in these cases, which we believe constitute an exception, the ES should be assigned to the breed-farming system association.

Breeds are more strongly related to some ES than others. The effect of species, stocking densities and the spatial distribution of farms have a much larger effect on regulating ES than do specific breeds per se. Regulating ES should only be related to breeds if they are part of a breed-farming system association. For example, in the case of extreme breed differences, say replacing local cattle breeds by Holstein, the change in regulating ES (e.g. prevention of forest fires due to grazing), would be a consequence of the deep modification of the farming system. The linkage between livestock breeds and provisioning ES is rather straightforward through specific breed-related products and services (e.g. cashmere goats). Breeds, as a human-made concept, have strong links with cultural ES. Breed-related cultural ES depend heavily on the value that societies place on breeds as part of their heritage. For example, some breeds have become elements of cultural identity or are related to aesthetic experiences (e.g. Ankole cattle for the identity of Ankole people in Uganda). However, not all breeds are linked to cultural elements due to the fact that these cultural elements are local, and not all local breeds have the same cultural value, as proposed by Marsoner et al. (2018).

The demands for novel agrifood chains that respect planetary boundaries, animal welfare and human health, call for a deep reconfiguration of animal production, opening new opportunities for pastoral systems and local breeds. The ES 
framework can contribute to highlight the different private and public outcomes from farm animals and breeds, in particular, within the farming systems in which they are integrated. The contribution of specific breeds to provisioning and cultural ES is apparent; however, their role in delivering regulating $\mathrm{ES}$ is questionable.

\section{Acknowledgements}

None.

(D) D. Martin-Collado 0000-0002-2087-961X

A. Bernués 0000-0002-3237-9751

\section{Declaration of interest}

The views and opinions expressed in this article are those of the authors. These do not necessarily reflect the official policy or position of FAO.

\section{Ethics statement}

None.

\section{Software and data repository resources}

None.

\section{References}

Haines-Young $R$ and Potschin M 2010. The links between biodiversity, ecosystem services and human well-being. In Ecosystem ecology: a new synthesis (ed. D Raffaelli and C Frid), pp. 110-139. Cambridge University Press, Cambridge, UK.

Leroy G, Baumung R, Boettcher P, Besbes B, From T and Hoffmann I 2018 Animal genetic resources diversity and ecosystem services. Global Food Security 17, 84-91.

Liu J, Dietz T, Carpenter SR, Alberti M, Folke C, Moran E, Pell AN, Deadman P, Kratz T, Lubchenco J, Ostrom E, Ouyang Z, Provencher W, Redman CL, Schneider $\mathrm{SH}$ and Ostrom E 2007. Complexity of coupled human and natural systems. Science 317, 1513-1516.

Marsoner T, Vigl LE, Manck F, Jaritz G, Tappeiner U and Tasser E 2018. Indigenous livestock breeds as indicators for cultural ecosystem services: a spatial analysis within the Alpine Space. Ecological Indicators 94, 55-63.

Ovaska U and Soini K 2016. Native breeds as providers of ecosystem services: the stakeholders' perspective. Finnish Journal for Human-Animal Studies 2 , $28-51$. 